\title{
ПРОБЛЕМЫ КАВКАЗСКОЙ ПОЛИТИКИ ИРАНА В ПЕРИОД ВООРУЖЕННОГО КОНФЛИКТА В НАГОРНОМ КАРАБАХЕ (1991-1994 гг.)
}

В статье анализируется кавказское направление внешней политики Исламской Республики Иран в постсоветский период; вскрываются проблемы, с которыми сталкивалось руководство страны в ходе еe реализации. Выявлена высокая заинтересованность Тегерана в усилении иранского влияния в Южном Кавказе после распада СССР и ослабления в регионе позиций России. Показано острое соперничество Ирана с Турцией за преимущественное влияние в Южном Кавказе, усиление в регионе своих политико-экономических позиций. Анализируются действия руководства Ирана в ходе вооруженного конфликта в Нагорном Карабахе; отмечено его беспокойство из-за возможного разрастания конфликта, вовлечения в него азербайджанского этнического меньшинства, проживающего на северо-западе Ирана Раскрывается роль «азербайджанского фактора» в политике Ирана в южно-кавказском направлении; выявляются причины сложившихся сложных взаимоотношений
Исламской Республики с Азербайджаном - с одной стороны, и ее высокой заинтересованности в налаживании тесных связей с Арменией - с другой. Анализируется воздействие различных факторов на амбивалентную позицию иранского руководства в вопросе мирного урегулирования Нагорно-Карабахского конфликта. Доказана необходимость внесения качественных изменений во внешнеполитическую деятельность Ирана в южно-кавказском направлении, придания ее политике в регионе более сбалансированного характера. При этом подчеркивается, что сбалансированный внешнеполитический курс иранского руководства отвечал интересам национальной безопасности страны, заинтересованного в снижении общего уровня напряженности в регионе Южного Кавказа.

Ключевые слова: Южный Кавказ, нестабильность Иран, амбивалентная политика, «азербайджанский фактор», Нагорный Карабах, конфликт.

A. K. Dudayti

\section{THE PROBLEMS OF THE CAUCASIAN POLICY OF IRAN DURING THE ARMED} CONFLICT IN NAGORNO-KARABAKH (1991-1994)

The article analyzes the Caucasian direction of the foreign policy of the Islamic Republic of Iran in the post-Soviet period; the study reveals the problems faced by the country's leadership in the course of its implementation. Tehran's high interest in strengthening Iranian influence in the South Caucasus after the collapse of the USSR and the weakening of Russia's positions in the region is revealed. The sharp rivalry between Iran and Turkey for the predominant influence in the South Caucasus and the strengthening of its political and economic positions in the region are shown The author analyzes the actions of the Iranian leadership during the armed conflict in Nagorno-Karabakh and notes the concern over the possible expansion of the conflict and the involvement of the Azerbaijani ethnic minority living in the north-west of Iran. The role of the "Azerbaijani factor" in Iran's policy in the South Caucasus is revealed; the rea-

После распада СССР между двумя региональными державами - Ираном и Турцией, усилилось соперничество за преимущественное влияние и позиции в республиках с мусульманским населением, возникших на постсоветском пространстве Прежде всего оно приняло форму соперничества «Турецкой модели развития», модели светского государства с мусульманским населением, являющегося проводником западных идей и настро- sons for the complex relations of the Islamic Republic with Azerbaijan, on the one hand, and its high interest in establishing close ties with Armenia, on the other hand, are given. The impact of various factors on the ambivalent position of the Iranian leadership on the peaceful settlement of the Nagorno-Karabakh conflict is analyzed. The necessity of making qualitative changes in Iran's foreign policy in the South Caucasus direction, giving its policy in the region a more balanced character is proved. At the same time, it is emphasized that the balanced foreign policy of the Iranian leadership was in the interests of the national security of the country, focused on reducing the overall level of tension in the South Caucasus region.

Key words: South Caucasus, instability, Iran, ambivalent policy, "Azerbaijani factor", Nagorno-Karabakh, conflict.

ений в постсоветских республиках, с «иранской моделью развития», основанной на радикальном исламском мировоззрении, с шиитским духовенством, стоящим у власти, контролирующим и инициирующим все основные социально-политические и экономические процессы в Иране. В ходе этого соперничества постепенно стало выявляться превосходство Турции, поскольку политические элиты постсоветских республик в большей 
степени склонялись к принятию «турецкой модели" для развития своих стран. В то же время они негативно относились к политическому исламу, что в свою очередь сдерживало их в развитии тесных связей с Ираном.

В ирано-турецком соперничестве важное место занимал район Кавказа, в прошлом являющийся объектом военно-политического противоборства между Российской, Персидской и Османской империями [14]. Особенно острый характер оно приобрело в Южном Кавказе - важнейшем стратегическом регионе Евразии, где проходили крупные торговые пути, связывающие Европу с Азией. Противоборствующие между собой империи неизменно считали регион Южного Кавказа зоной своего исключительного влияния (подробнее см. [1]).

В результате последовавшего за распадом СССР ослабления российского влияния в Южном Кавказе в руководстве Ирана возросла заинтересованность в восстановлении позиций страны в этом регионе. Учитывая религиозное влияние Ирана и этническое - из Турции, можно было предположить, что в кавказской стратегии этих стран предпочтение будет отдано Азербайджану. В свою очередь, политические элиты этой республики стремились использовать ирано-турецкое соперничество в своих интересах. С Турцией азербайджанцев связывала общая языковая группа (тюркская), эти народы были весьма близки на культурном и ментальном уровне. В свою очередь, ирано-азербайджанские отношения имели богатую историю в составе Персидской империи; на северо-западе Ирана с давних времен проживало азербайджанское этническое меньшинство, наконец, иранцы и азербайджанцы исповедовали единое, шиитское направление ислама. Последнее обстоятельство во многом обусловило выбор Азербайджана в деле усиления иранского влияния на Кавказе; другим фрактором, воздействующим на такой выбор, являлись богатые энергетические ресурсы Азербайджана, а также общая граница протяженностью более $700 \mathrm{kм}$.

В то же время на развитие тесных связей между двумя странами негативно влияло то обстоятельство, что политическая элита Азербайджана стремилась использовать в своих политических целях этнический фактор: в частности в Баку звучали призывы денонсировать договоры, закрепившие южные границы республики, чтобы добиться получения азербайджанцами статуса «разделенной нации», а затем выдвинуть требования о воссоединении азербайджанского этнического меньшинства в Иране (Южный Азербайджан) с его северным собратом - Республикой Азербайджан. Власти Ирана болезненно реагировали на эти призывы: раздавались угрозы в корне пересмотреть Туркманчайский договор 1898 г., по которому территория Азербайджана была выделена из состава Персии и включена в состав России [2]. Кроме того, в Тегеране с опасением следили за тем, как развиваются тесные связи между Азербайджаном и Турцией, союзником США по НАТО. Наконец, иранских духовных лидеров раздражал выбор Азербайджаном свет- ской модели развития, что крайне затрудняло религиозную деятельность в республике.

Указанные обстоятельства наложили свой отпечаток на противоречивый подход руководства Ирана к развитию отношений со своим северным соседом. На фоне быстро развивающихся турецко-азербайджанских связей политика Ирана в азербайджанском направлении выглядела пассивной. Власти Турции активно поддержали Азербайджан в Нагорно-Карабахском конфликте турки незамедлительно присоединились к блокаде, введенной Азербайджаном против Армении. В то же время, руководство Ирана заняло амбивалентную позицию в конфликте: по сути, оно дистанцировалось от движущих его сил, ограничившись заявлениями о необходимости мирного разрешения конфликта

Учитывая воинствующую риторику в Иране, можно было предположить, что Исламская Республика решительно встанет на сторону своих единоверцев - шиитов-азербайджанцев в противостоянии с армянами-христианами. Но этого не произошло: давая понять азербайджанскому и армянскому руководству, что Иран может выступить посредником в мирном урегулировании конфрликта, его руководители на деле заняли в нем армянскую сторону. В Иране с давних времен рассматривали Армению, как своего «младшего партнера» в геополитическом противостоянии с Турцией и доброжелательно относились к ней [4]. В ходе вооруженного конфлликта в Нагорном Карабахе ирано-армянская граница оказалась спасительным выходом из той сложной ситуации, которая возникла вследствие введения турецко-азербайджанской блокады Армении. Кроме того, иранцы помогали Нагорному Карабаху, снабжая его продовольствием и другими товарами [7].

В целом, анализируя иранскую стратегию в период Нагорно-Карабахского конфликта, следует отметить воздействие на нее «азербайджанского фрактора». Из-за усилившегося сепаратизма среди азербайджанского населения на северо-западе Ирана руководители этой страны негативно относились к Азербайджану, противодействовали реализации его планов в ходе противостояния с Арменией из-за Нагорного Карабаха. Они проводили эту линию, несмотря на настойчивые призывы лидеров иранских азербайджанцев активно поддержать их собратьев в конфликте с армянскими «неверными» [6, с. 312]. Игнорирование властями этих призывов следовало объяснить опасением, что в результате активных контактов населения Азербайджанской республики с иранскими азербайджанцами среди последних мог усилиться сепаратизм, угрожающий территориальной целостности Исламской Республики.

Угроза центробежных тенденций в Иране заметно возросла летом 1993 г., когда после занятия армянскими силами территории на юге Азербайджана тысячи беженцев хлынули к иранской границе. Часть их пересекла границу и была принята иранскими азербайджанцами. В создавшейся сложной ситуации, чтобы пресечь наплыв беженцев в Иран, центральным правительством 
было принято решение о создании для них палаточных лагерей на юге Азербайджана. Осенью 1993 г. туда было отправлено более 40 тыс. чел. перебравшихся ранее в северо-западный регион Ирана [6, с. 313].

Иранские власти противодействовали наплыву беженцев в страну из-за опасения, что они могут склонить местных этнических азербайджанцев к оказанию активной поддержки своим соплеменникам в вооруженном конфликте с армянами. С этой целью они могли оказать давление на центральные власти, требуя вмешательства Ирана в Нагорно-Карабахский консоликт на стороне Азербайджана. Еще большую опасность представляла перспектива проведения мобилизации добровольцев среди этнических азербайджанцев с последующей отправкой в район боевых действий на помощь азербайджанским вооруженным силам.

Таким образом, угроза роста сепаратизма оказывала сдерживающее воздействие на позицию властей Ирана в ходе Нагорно-Карабахского конфликта. Хотя в начале конфликта из лагеря иранских националистов звучали требования активно поддержать азербайджанцев; при этом националисты напоминали, что в прошлом территория Северного Азербайджана входила в состав Персидской державы [6, с. 314]. Однако эти настроения кардинально изменились после прихода к власти в Азербайджане в июне 1992 г лидера оппозиционного Народного Фронта Азербайджана (НФА) А. Эльчибея. Будучи приверженцем идеологии пантюркизма, этот деятель стал выступать за воссоединение северо-западных территории Ирана с проживающим там азербайджанским этническим меньшинством с Peспубликой Азербайджан и создание на этой основе нового государства [3]. В период правления А. Эльчибея главным приоритетом внешней политики Азербайджана являлось развитие тесных связей с Турцией и ведущими западными странами, прежде всего с США и Великобританией Новый лидер Азербайджана открыто занял недружественную позицию в отношении Москвы и Тегерана и всячески старался раздражать российское и иранское руководство. В результате в непростых взаимоотношениях Азербайджана с Россией и Ираном вполне предсказуемо появились новые элементы взаимной отчужденности

Между тем руководство А. Эльчибея, состоящее в основном из активистов НФА, оказалось не в силах преодолеть хаос и дезорганизацию в республике, вызванных поражениями на карабахском фронте. В результате противостояния угрожавшего развалом страны, А. Эльчибей был отстранен от власти, а его место в июне 1993 г занял Г. Алиев. Деятели НФА были склонны считать Москву и Тегеран косвенными виновниками насильственной смены власти в республике, однако доказательств в подтверждение таких обвинений не было представлено. Между тем фактом являлось то, что в период правления А. Эльчибея произошла трансформация в подходе Ирана к проблеме урегулирования коноликта в Нагорного Карабаха в сторону преимущественного учета ин- тересов Армении. В ответ усилились критические выступления азербайджанских политиков в адрес властей Ирана: к обвинениям в тайном пособничестве Тегерана осуществлению государственного переворота добавились новые - поддержка радикальных исламских движений в Азербайджане, а также содействие межэтническому противостоянию в республике путем поддержки сепаратистских настроений среди талышского этнического меньшинства, проживающего на приграничных с Ираном территориях страны.

Новое руководство во главе с Г. Алиевым взяло курс на нормализацию отношений Азербайджана с Россией и Ираном; были также приняты меры для придания азербайджанской политике сбалансированного характера, в частности, подверглась пересмотру внешнеполитическая линия на однобокую ориентацию на Турцию. Следуя в этом направлении, в сентябре 1993 г. Азербайджан вступил в СНГ. Одновременно руководство Г. Алиева стремилось сблизить республику с ведущими странами исламского мира (кроме Турции), в расчете заручиться их поддержкой в противостоянии с Арменией из-за Нагорного Карабаха. С этой целью Г. Алиев неоднократно посещал Иран и Саудовскую Аравию и во время официальных встреч с руководством этих стран обсуждал проблемы, связанные с кризисом вокруг Нагорного Карабаха, а также пути выхода из него [12].

Однако активность азербайджанской дипломатии в иранском направлении не привела к заметному улучшению взаимоотношений между Баку и Тегераном. Как и прежде, позиция Ирана в Нагорно-Карабахском конфликте склонялась в сторону преимущественного учета армянских интересов. Больше того, уровень взаимоотношении двух стран опустился до нижней отметки, когда бакинские власти в результате давления на них со стороны администрации США отказали Ирану в 5\% долевом участии в масштабном нефтяном контракте с иностранным участием (13 компаний из 8 стран), заключенного в Баку в сентябре 1994 г. В Тегеране расценили это действие, как послушное следование Азербайджана в фарватере США«Великой Сатаны» [6, с. 315]. В ответ незамедлительно было прекращено энергоснабжение Нахичевани из Ирана. При этом было заявлено, что правительство Ирана вынуждено прибегнуть к этой мере, поскольку власти автономной республики не могут погасить накопившиеся долги за предыдущие поставки электроэнергии [10].

В последующий период правительство Ирана всячески создавала препоны реализации различных проектов экспорта азербайджанской нефти через свою территорию. Так, азербайджанской стороне не разрешили проложить трубы по территории Ирана в рамках реализации проекта нефтепровода Баку-Джейхан. В Тегеране свое согласие с этим проектом непосредственно увязывали с важным условием, а именно: нефтепровод должен был выйти не на территорию Турции, а в Персидский залив. Тем самым иранцы получали возможность вести контроль за экспортом азербайджанской нефти и соответственно - ока- 
зывать воздействие на политику бакинских властей [6, с. 315-316]. В этих условиях, стремясь наладить взаимоотношения с Ираном, руководство Азербайджана предложила иранской стороне $10 \%$ долевое участие в разработке другого месторождения нефти - Шах-Дениз. В Тегеране сначала проигнорировали это предложение, но затем, исходя из прагматических соображений, решили принять его [11].

Хотя некоторые подвижки в налаживании экономического сотрудничества между Ираном и Азербайджаном были налицо, в целом двусторонние отношения продолжали пребывать в состоянии кризиса. Во многом это следовало объяснить продолжающимся конфликтом в Нагорном Карабахе, в результате которого регион Южного Кавказа превращался в зону международной напряженности [9, с. 30]. Для преодоления этой угрозы в Тегеране заняли позицию урегулирования конфликта исключительно мирными средствами, в рамках существующих норм международного права. В соответствии с этой позицией руководство Ирана предложило свои посреднические услуги конфликтующим сторонам, однако уже первый его опыт посредничества оказался неудачным. Речь идет о достигнутом в Тегеране 7 мая 1992 г. между главами Азербайджана и Армении согласии на посредничество спецпредставителя президента Ирана в деле прекращения огня и открытии всех коммуникационных дорог в конорликтной зоне. Это соглашение вскоре было нарушено взятием армянскими силами г. Шуши, главного опорного пункта азербайджанских военных сил в регионе. Другим важным фактором, по сути сводящим на нет усилия иранской дипломатии, было негативное отношение к Тегерану со стороны правительства НФА во главе с А. Эльчибеем, его упорное нежелание видеть Иран среди движущих сил-посредников в урегулировании конфоликта в Нагорном Карабахе [13].

Тем не менее, Нагорно-Карабахский конфликт активно использовался руководством Ирана для успешной реализации стратегических целей своей страны в Южном Кавказе. После перерастания конфликта в вооруженную фазу в Тегеране стремились оказывать влияние на азербайджанское руководство, прибегая для этого к оказанию косвенной поддержки армянской стороне. Хотя были случаи, когда власти Ирана выступили с жестким осуждением действий армянских вооруженных сил в зоне конфликта. Такой факт имел место в мае 1992 г., когда нападению подвергся Нахичевань, имеющий общие границы с Турцией и Ираном. Руководители этих стран обратились в Совет Безопасности ООН с просьбой осудить армянскую агрессию, после чего в Ереване заверили, что Нахичевань не подвергнется больше вооруженной атаке. Сложная ситуация в ирано-армянских отношениях возникла и в ноябре 1993 г., когда в результате оккупации армянскими силами районного центра Зангелан на юге Азербайджана находящееся там формирование азербайджанских вооруженных сил вынуждено было переправиться через р. Аракс и вступить в преде- лы иранской территории. В Тегеране были крайне обеспокоены этим фактом, угрожающим безопасности приграничным с Азербайджаном иранским территориям. За исключением этих случаев, когда критика в адрес Еревана была обусловлена опасением разрастания конфллика на иранскую территорию, в Тегеране не скрывали своей поддержки Армении. Как указывалось выше, из Ирана осуществлялось энергоснабжение Армении и Нагорного Карабаха, поставлялись туда продукть питания, другие товары, что имело для армянского населения этих регионов важное значение в условиях турецко-азербайджанской блокады.

В ходе реализации внешнеполитических целей и задач Азербайджана в Южном Кавказе руководство этой страны неизменно наталкивалось на активное противодействие со стороны Москвы и Тегерана. Что же касается поддержки республики со стороны союзника - Турции, то она далеко не всегда выглядела активной: в Анкаре предпочитали с осторожностью действовать в направлении Южного Кавказа, избегая вовлеченности своей страны в Нагорно-Карабахский конфликт. Между тем азербайджанские власти демонстрировали свое бессилие в деле нормализации обстановки в стране. Такой результат являлся следствием явной неспособности А. Эльчибея взять на себя роль государственного деятеля и одновременно, действиями против его правительства со стороны внешних сил.

Между тем создавшаяся в Южном Кавказе взрывоопасная ситуация из-за обострения Нагорно-Карабахского конфликта требовала принять срочные меры, чтобы начать переговорный процесс по его мирному урегулированию [5]. Во властных кругах Ирана возобладало мнение, что преимущественная поддержка Армении в конфлликте может иметь негативные последствия для страны, имея в виду угрозу ее безопасности вследствие роста напряженности в регионе. По мнению многих наблюдателей, существовала опасность перерастания конфликта в Нагорном Карабахе в более масштабное противостояние в регионе, с участием России, Ирана и Турции. При этом Ирану грозила прямая вовлеченность в этот региональный конфликт, имея в виду наличие у него общих границ с Арменией и Азербайджаном, а также нестабильное положение на северо-западе страны с проживающим там азербайджанским населением. Поэтому мирное разрешение конфликта в Нагорном Карабахе прямо отвечало национальным интересам Ирана. Казалось бы, осознание этого очевидного фракта должно было оказать стимулирующее воздействие на продолжение посреднических усилий властей Ирана [8, с. 84], однако под воздействием целого ряда факторов, действующих как внутри страны, так и за ее пределами, они не были реализованы.

Таким образом, в результате распада СССР появились новые вызовы и угрозы для национальной безопасности Исламской Республики Прежде всего, возникла нестабильная ситуация в северо-западных территориях страны из-за вооруженного противостояния между Азербайджа- 
ном и Арменией вокруг Нагорного Карабаха. Часть азербайджанского населения на этих территориях оказалась втянутой в этот, что уже угрожало существованию самого иранского государства В Тегеране полагали, что наибольшая опасность безопасности Ирана исходит от Азербайджана, чьи лидеры поддерживали сепаратистские настроения среди азербайджанского этнического меньшинства на северо-западе страны. Исходя из этого в Тегеране всячески старались противодействовать планам развития Азербайджана поддержали Армению в Нагорно-Карабахском конфликте. Однако такая политика не принесла Ирану желаемых результатов: наоборот, росла напряженность в регионе, создавая новые угрозы безопасности иранского государства. В сложившейся ситуации становилось очевидным, что лидерам Ирана необходимо внести существенные коррективы в свою политику в южно-кавказском направлении, прежде всего, придать ей сбалансированный характер, подразумевающий поддержание высокого уровня взаимоотношений с Арменией и Азербайджаном. Только таким путем можно было рассчитывать на усиление иранских позиций в Южном Кавказе, что полностью подтвердилось в ходе дальнейшего развития событий в регионе.

\section{Источники и литература / References}

1. Дудайти А. К. Место Грузии в «восточной» политике России периода нового времени // Научные Ведомости Белгородского государственного университета. Серия: История. Политология. Экономика. Информатика. 2013. №22(165) C. 79-86.

Dudayti A. K. Mesto Gruzii v «vostochnoj» politike Rossii perioda novogo vremeni (The Place of Georgia in the "Eastern" Policy of Russia in the New Time Period) // Nauchnye Vedomosti Belgorodskogo gosudarstvennogo universiteta. Seriya: Istoriya. Politologiya. Ekonomika. Informatika. 2013. No. 22 (165). P. 79-86. (In Russian).

2. Лебанидзе С. Ирано-азербайджанские отношения с напряжением. URL: http://www.bilgesam.org/ru/incele/1538/ru/\#.XBo-j1wzaM8 (Дата обращения: 17.10.2018).

Lebanidze S. Irano-azerbajdzhanskie otnosheniya s napryazheniem. (Iranian-Azerbaijani Relations with Tension). URL: http://www.bilgesam.org/ru/incele/1538/-ru/\#.XBo-j1wzaM8 (Accessed: 17.10.2018). (In Russian).

3. Полонский И. Сепаратизм в Иране: разрушать ли единство страны внутренние конфликты? URL: https://topwar. ru/86067-separatizm-v-irane-razrushat-li-edinstvo-strany-vnutrennie-konflikty.html (Дата обращения: 20.10.18).

Polonskij I. Separatizm v Irane: razrushat' li edinstvo strany vnutrennie konflikty? (Separatism in Iran: Will Internal Conflicts Destroy the Unity of the Country?). URL: https://topwar.ru/86067-separatizm-v-irane-razrushat-li-edinstvo-strany-vnutrenniekonflikty.html (Accessed: 20.10.2018). (In Russian).

4. Проценко Н. В Карабахский конфликт хочет вмешаться Иран. URL: https://vz.ru/world/2016/4/15/805430.html (Дата обращения: 21.10 .2018 )

Protsenko N. V Karabakhskij konflikt khochet vmeshat'sya Iran. (Iran Wants to Intervene in the Karabakh Conflict). URL https://vz.ru/world/2016/4/15/805430.html (Accessed: 21.10.2018). (In Russian).

5. Cornell S.E. Peace or War? The Prospects of Conflicts in the Caucasus // Iranian Journal of International Affairs. 1997.

No. 2. URL: https://aheku.net/articles/english/general/1138 (дата обращения 23.10.2018).

6. Cornell S.E. Small Nations and Great Powers: A Study of ethnopolitical Conflict in the Caucasus. London: Taylor \& Francis Group, 2005.

7. Enclave Builds a Lifeline Out of Azerbaijan // International Herald Tribune. 1996. September 20.

8. Halliday F. Condemned to React. Unable to Influence: Iran and Transcaucasia // Transcaucasian Boundaries; (ed. J. F. Wright, S. Goldenberg, R. Schoefield. London: UCL Press, 1996.

9. Herzig E. Iran and the Former Soviet South. London: Royal Institute for International Affairs, 1995

10. Iran Cuts Electricity to Nakhichevan // OMRI Daily Digest. 1995. 30 May.

11. Iran Finally Agrees to Stake in Shah-Deniz // OMRI Daily Digest. 1996. 13 May

12. Kechichian J. A., Karasik Th. W. The Crisis in Azerbaijan: How Clans Influence the Politics of an Emerging Republic // Middle East Policy. 1996. P. 64-65.

13. Ramezanzadeh A. Iran's Role as Mediator in the Nagorno-Karabakh Crisis // Contested Borders in the Caucasus / ed B. Coppieters. URL: http://poli.vub.ac.be/publi/ContBorders/eng/ch0701.htm (дата обращения: 22.10.2018).

14. Stecchini L.C. History of Iran. The Persian Wars. Iran Chamber Society. URL: http://www.iranchamber.com/ history/ articles/persian_wars3.php (дата обращения: 23.10.2018).

\section{Сведения об авторе}

Дудайти Альберт Константинович - доктор исторических наук, профессор кафедры всеобщей истории и политологии исторического фракультета Северо-Осетинского государственного университета им К. Л. Хетагурова (Владикавказ) / adudaiti@mail.ru

\section{Information about the author}

Dudayti Albert - Dr. of Historical sciences, Professor, Chair of Modern, Contemporary History and Historical Political Sciences Faculty of History of Ossetian State University (Vladikavkaz) / adudaiti@mail.ru 